\title{
A Novel Patient-Specific Drill Guide Template for Pedicle Screw Insertion into the Subaxial Cervical Spine Utilizing Stereolithographic Modelling: An In Vitro Study
}

\author{
Rafael Cruz Bundoc ${ }^{1}$, Giorgio De Guzman Delgado ${ }^{2}$, Samuel Arsenio Munoz Grozman ${ }^{1}$ \\ ${ }^{1}$ Section of Spine Surgery, Department of Orthopedics, Philippine General Hospital, University of the Philippines, Manila, Philippines \\ ${ }^{2}$ Department of Orthopedics, Philippine General Hospital, University of the Philippines, Manila, Philippines
}

Study Design: Cadaveric study.

Purpose: The purpose of this study was to assess the accuracy and feasibility of cervical pedicle screw (CPS) insertion into the subaxial cervical spine placed using a patient-specific drill guide template constructed from a stereolithographic model.

Overview of Literature: CPS fixation is an invaluable tool for posterior cervical fixation because of its biomechanical advantages. The major drawback is its narrow corridor that allows very little clearance for neural and vascular injuries.

Methods: Fifty subaxial pedicles of the cervical vertebrae from five cadavers were scanned into thin slices using computed tomography (CT). Digital imaging and communications in medicine images of the cadaver spine were digitally processed and printed to scale as a three-dimensional (3D) model. Drill guide templates were manually moulded over the 3D-printed models incorporating pins inserted in the pedicles. The drill guide templates were used for precise placement of the drill holes in the pedicles of cadaveric specimens for pedicle screw fixation.

Results: The instrumented cadaveric spines were subjected to CT to assess the accuracy of our pedicle placement by an external observer. Our patient-specific drill guide template had an accuracy of $94 \%$.

Conclusions: The use of a patient-specific drill guide constructed using stereolithography improved the accuracy of CPS placement in a cadaveric model.

Keywords: Subaxial cervical spine; Cervical pedicle screw fixation; Three-dimensional printing; Stereolithography; Patient-specific surgical template

\section{Introduction}

Posterior stabilization of the subaxial cervical spine (C3C7) has tremendously improved with the introduction of screw/rod/plate fixation techniques during the last two decades $[1,2]$. The lateral mass of the facets and the pedicles offer the viable osseous densities where screw systems can be safely anchored. Biomechanical studies show that cervical pedicle screw (CPS) fixation has greater stability than lateral mass screws $[3,4]$. However, it remains techni-

\footnotetext{
Received Apr 5, 2016; Revised Jun 7, 2016; Accepted Jul 9, 2016

Corresponding author: Rafael Cruz Bundoc

Department of Orthopedics, Philippine General Hospital, University of the Philippines,

University of the Philippines Health Science Center, Taft Avenue, Ermita, Manila, PH 1000, Philippines

Tel: +632-5369605 , Fax: +632 5218538, E-mail: pipospine@gmail.com
} 
cally challenging to insert CPSs because of their small size and variable direction, notwithstanding their anatomical relationships to very delicate structures [5-8]. Numerous methods for accurate insertion of CPSs have evolved and include freehand techniques, fluoroscopy-guided techniques, and image-guided surgery (IGS) techniques.

The freehand technique is based on anatomical landmarks and averages morphometric angulations, which are used as guides to insert CPSs. However, anatomical variations and anatomical shifts related to patient positioning on the operating table make this technique unreliable [912]. Fluoroscopy-guided techniques expose the surgeon and patient to high levels of radiation, and the setup has a large equipment footprint that limits the surgeon's maneuverability [12-14]. Computer-assisted surgical navigation appears to have provided the ultimate accuracy in directing implant fixations, but not many centers have this expensive equipment $[12,13,15,16]$. Refinement of three-dimensional (3D) printing or stereolithography has enabled creation of detailed models of the spine and led to production of patient-specific surgical templates (PSSTs), which are used to precisely insert spinal implants into the anatomy of the vertebrae [17-20].

We developed a novel stereolithographic low-cost method for increasing the accuracy of CPS insertion. In this study, we used this innovative and highly accurate method involving stereolithographic $3 \mathrm{D}$ modeling to construct PSSTs for CPS insertion and determined the method's accuracy for insertion of pedicle screws in the subaxial cervical spine (C3-C7).

\section{Materials and Methods}

\section{1. $3 \mathrm{D}$ reconstruction of cervical models}

Fig. 1 briefly describes the methods. Twenty-five formalinpreserved articulated subaxial cervical vertebrae (C3-C7 vertebrae from five human cadavers) with no gross abnormalities were obtained from the Department of Anatomy, College of Medicine, University of the Philippines. Appendix 1 shows the profile of each cadaveric specimen. Each specimen was scanned using a Siemens Healthcare GmbH, Germany Somatom Definition AS (64-slice) computed tomography (CT) apparatus. Thin axial sections of $0.6-\mathrm{mm}$ thickness were taken to produce Digital Imaging and Communications in Medicine (DICOM) images of our specimen. The CT DICOM images of the cervical spine were loaded into a DICOM reader, which is an OsiriX v5.8.5-free software application (PixmeoSARL, Switzerland). This software was used to produce 3D-rendered digital images of all specimens. The same OSIRIX program was used to perform digital subtraction to only include the printing of the vertebral levels needed for the study $(\mathrm{C} 1-\mathrm{C} 7)$. The final 3D-rendered images were converted and exported in a stereolithographic file format “stl." (Fig. 2).

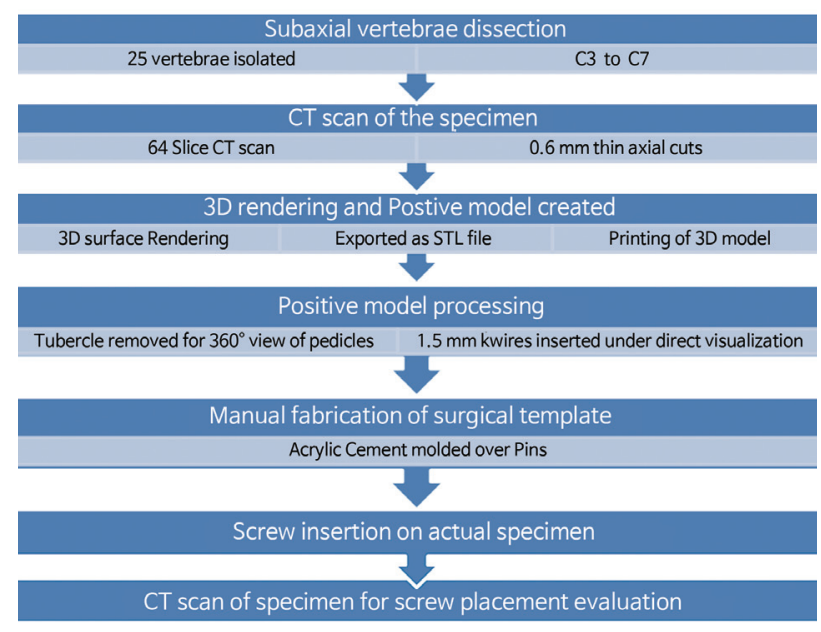

Fig. 1. Outline description of the methodology. CT, computed tomography; STL file, format is the universal language of 3D printing.

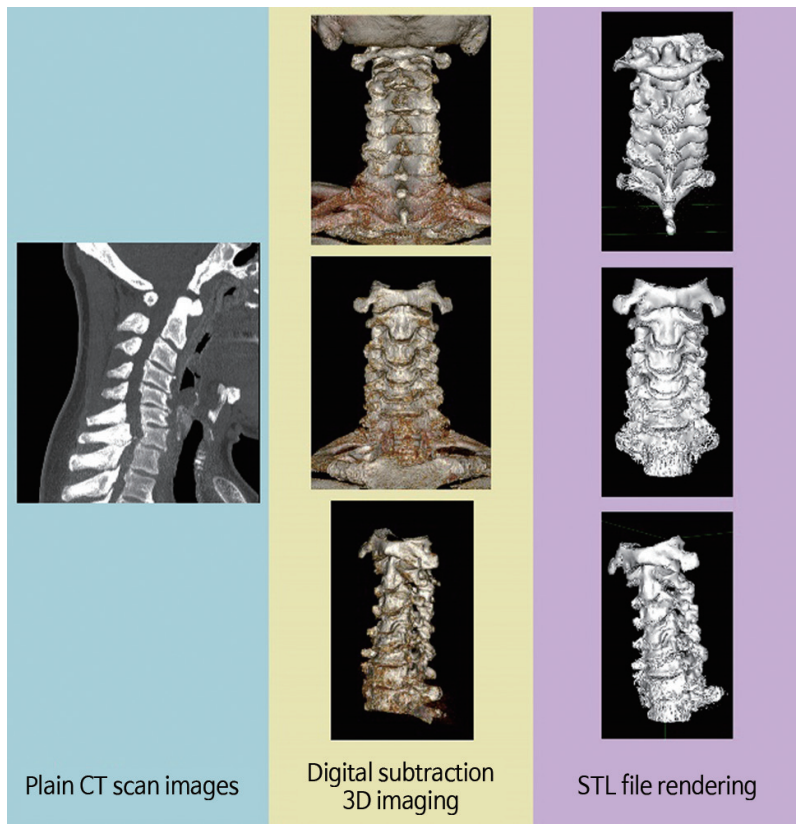

Fig. 2. Conversion of computed tomographic (CT) scan images into three-dimensional (3D) printable formats. Digital imaging and communications in medicine (DICOM) images converted to 3D-rendered images using a DICOM reader and exporting it as a ".stl" file format (".stl" file format is the universal language of 3D printing). 


\section{Production of biomodels and drill templates}

The exported "stl" files of the subaxial cervical vertebrae were loaded into a UP3D Plus 2 Personal Portable Office Desktop 3D printer (Beijing Tiertime Technology Ltd, Beijing, China). The latter was used to print exact 1:1 scale $3 \mathrm{D}$ replicas of all six cadaveric spine specimens that were made of acrylonitrile butadiene styrene (ABS) plastic built up using the Fused Deposition Technique (Fig. 3). These ABS plastic 3D-printed models can be drilled, sawed, and osteotomized in any fashion needed for the study. Twentyfive cervical vertebrae from five human cadavers (C3-C7 vertebrae of specimens A-F) were used.

After production of the $3 \mathrm{D}$ models, the anterior tubercle of the cervical models was rongeured to provide an almost $360^{\circ}$ view of the pedicles in all models. This allowed us to carefully drill and insert a 1.5-mm Kirschner wire through

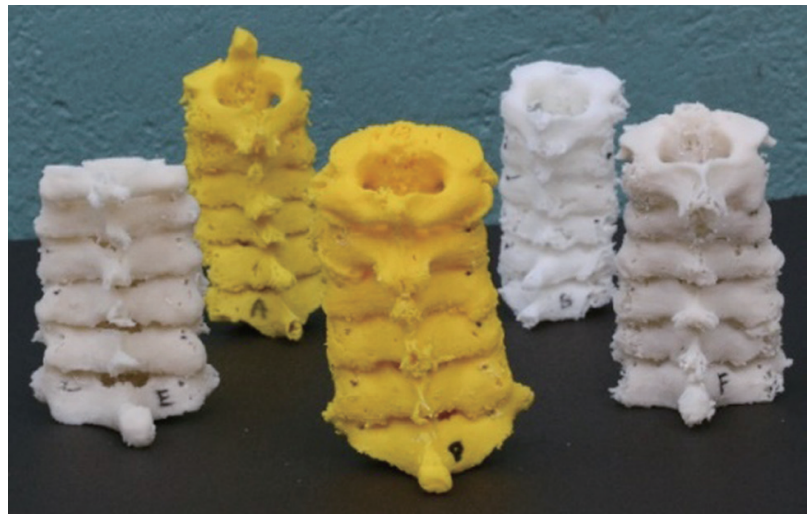

Fig. 3. Individual three-dimensional-printed ABS plastic models representing each of the cadaveric specimens.

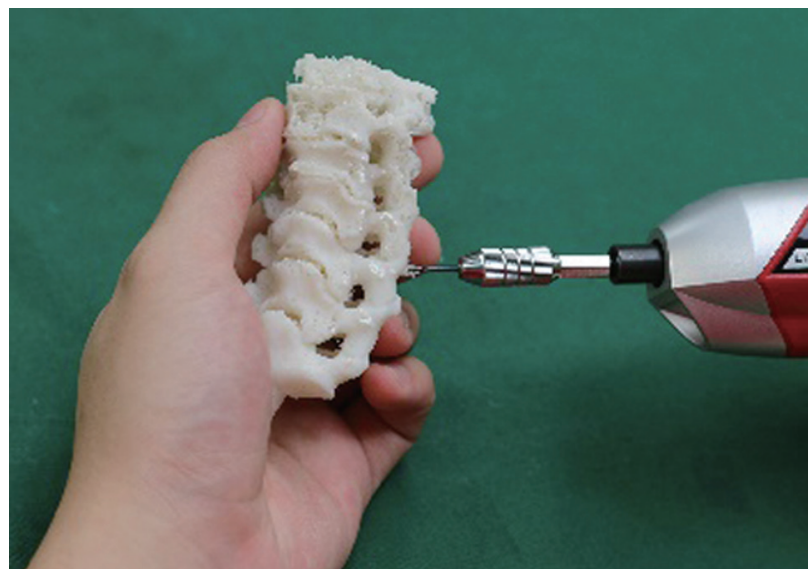

Fig. 4. Removal of the anterior tubercle of three-dimensional-printed cervical vertebrae provides a $360^{\circ}$ view of the pedicle, which allows precise insertion of Kirschner wires. the center of the 50 pedicles of the 25 subaxial vertebrae from the five 3D-printed cervical models representing our cadaveric specimens (Fig. 4). With the Kirschner wires accurately set in the specific direction of all 50 pedicles, we fashioned a drill jig template using a fast, self-curing polymethylmethacrylate, dental cement (Fig. 5). The latter was prepared by mixing one part of curing agent to three parts

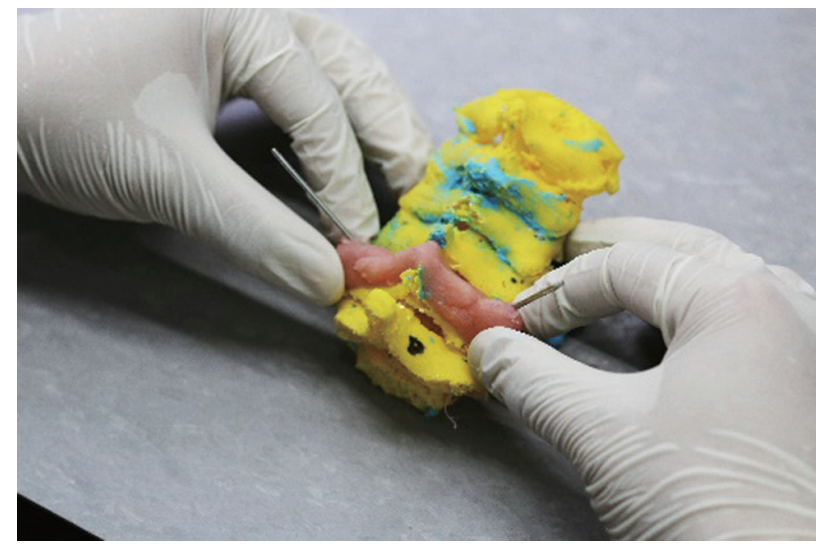

Fig. 5. Polymethylmethacrylate dental cement was molded on the posterior elements of the cervical spine models incorporating the Kirschner wires until it set into a firm molded drill guide.

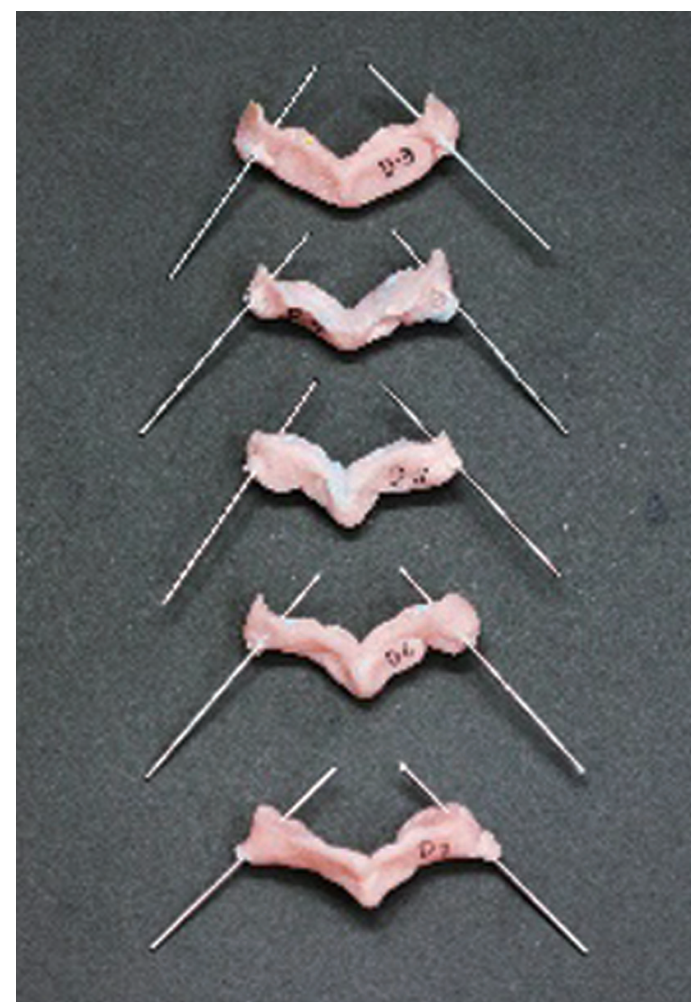

Fig. 6. Sample of drill jigs of the subaxial cervical spine (C3C7) with the attached Kirschner wires that are directed into the pedicles. 


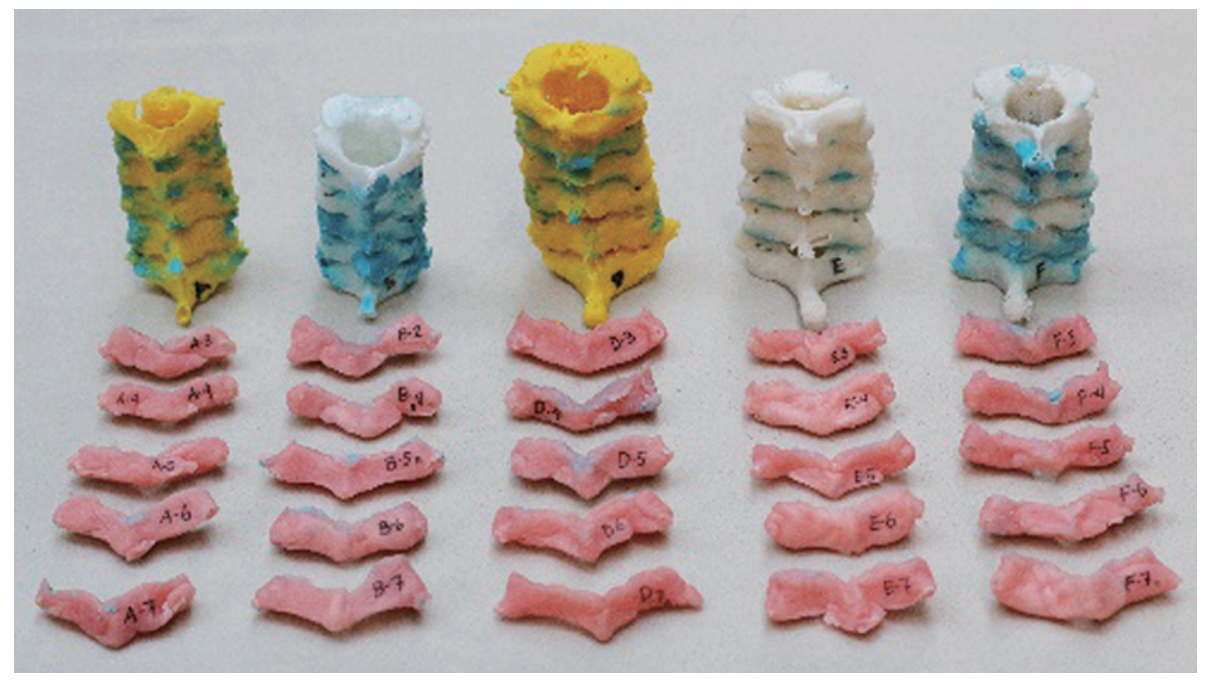

Fig. 7. Corresponding drill jigs for each of the three-dimensional-printed cadaveric spines.

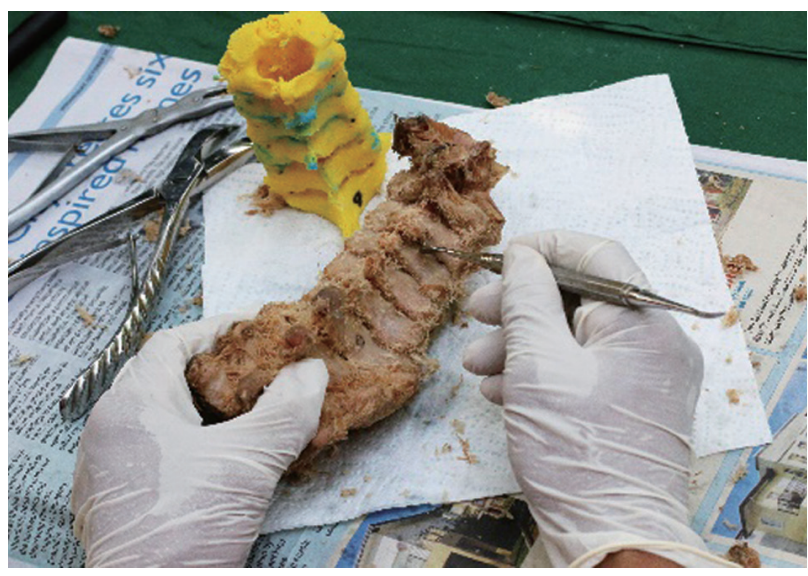

Fig. 8. Posterior soft tissue is removed from the cadaveric specimens to allow a snug fit for the drill jig templates.

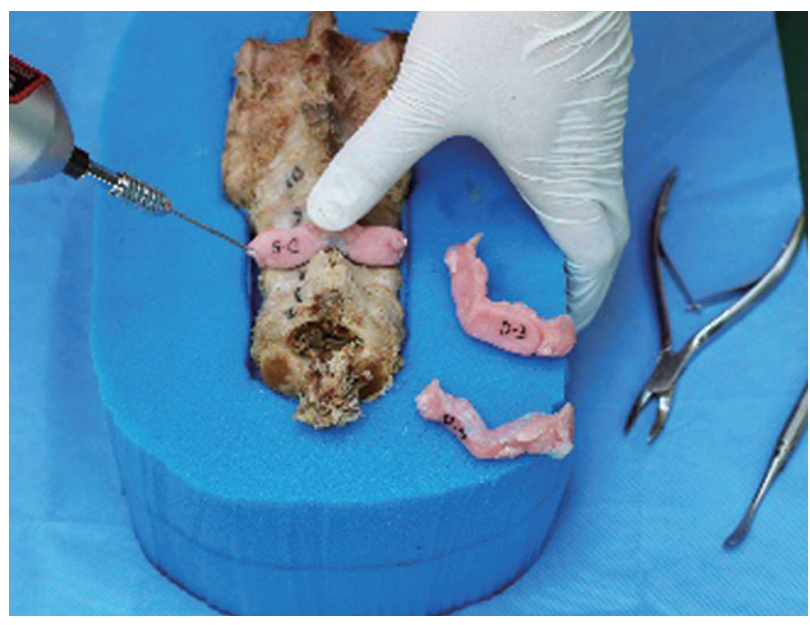

Fig. 9. The drill jigs are anchored to the posterior surface of the corresponding cervical vertebra. Kirschner wires are drilled through the trajectory of the drill jigs. of Duracryl self-cure, rapid-setting, dental acrylic cement. The procedure provided negative molds specific to the surface contour of the posterior elements (lamina, spinous process, and facets) of all $253 \mathrm{D}$-printed vertebrae (Fig. 6). After the final setting of the molded drill jig templates, the Kirschner wires were removed, thus providing study drill jigs specific to each of the 25 cervical vertebra (Fig. 7).

\section{Cadaveric transpedicular screw insertion}

All cadavers were prepared by removing all remaining posterior soft tissues simulating a clean subperiosteal dissection that is usually performed for posterior cervical surgical exposures (Fig. 8). The drill jigs were sequentially anchored to a snug fit on the posterior surface of its corresponding cervical vertebrae. A Kirschner wire was drilled into all cervical pedicles using the trajectories provided by each drill jig (Fig. 9). Through the channel provided by the Kirschner wires into the 50 pedicles, we used a cervical pedicle finder to enlarge the tracts for tapping. A 2.5$\mathrm{mm}$ tap was used to prepare the insertion of 3.5- and 4.0$\mathrm{mm}$ diameter GLOBUS cervical screws (Globus Medical Inc. Audubon, PA, USA) (Fig. 10). Because 3.5-mmdiameter screws were unavailable, we used 4.0-mm diameter screws for the remaining cadaveric specimens D-F.

\section{Assessment of accuracy of transpedicular screw placement}

Cervical anteroposterior, lateral, and bilateral oblique 

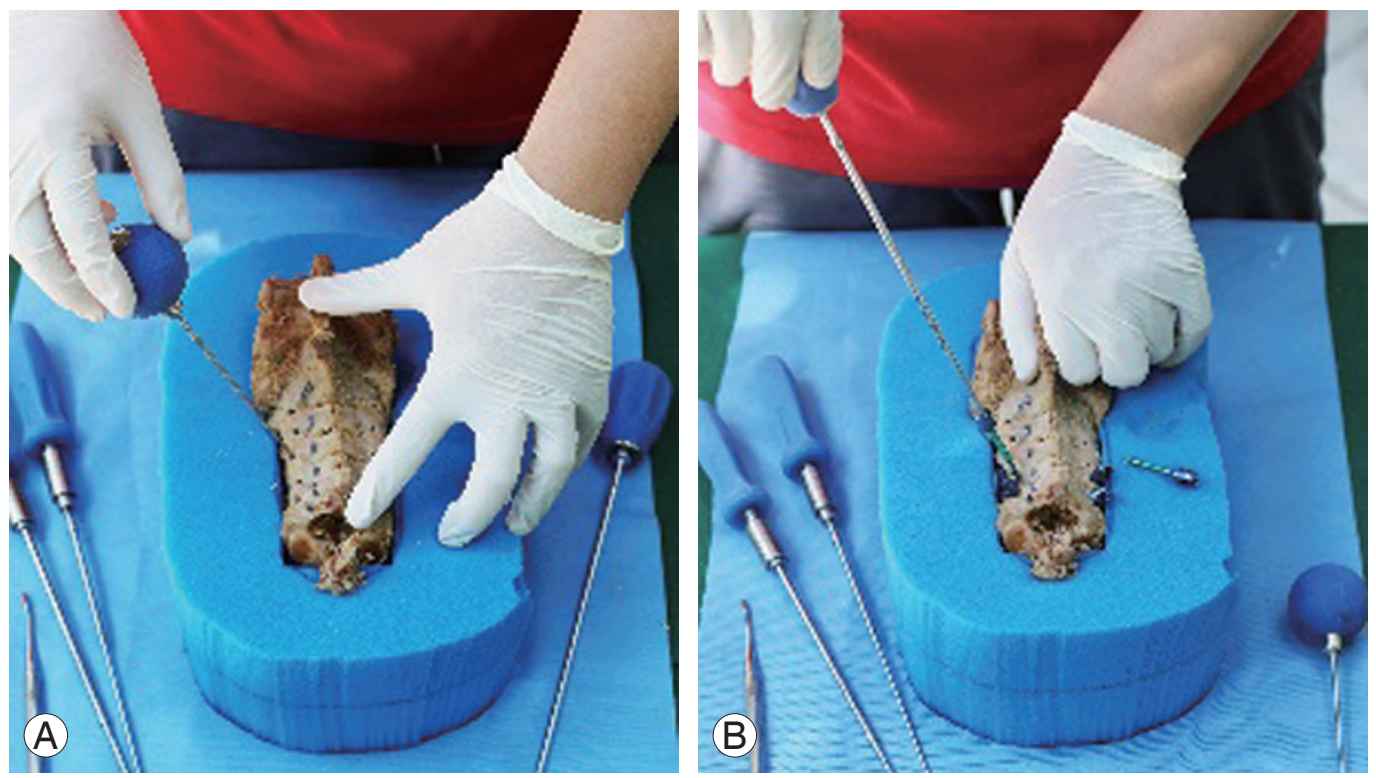

Fig. 10. The tract created by the Kirschner wire is enlarged using a cervical pedicle finder and prepared using a screw tap (A) prior to screw insertion (B).

radiographs were taken for all five specimen has no plural to grossly evaluate CPS placement. To determine the accuracy of our pedicle screw insertions, all five cadaveric specimen were again subjected to thin-slice $(0.6-\mathrm{mm})$ CT scan studies. The placement accuracy for all 50 pedicles was evaluated in the axial CT images and classified into three grades: grade 0 , correct placement; grade 1, malposition by less than a half screw diameter; and grade 2 , malposition by more than a half screw diameter [12]. The CT images were blindly evaluated by an independent spinal surgeon who was not involved in the 3D printing of the cadaver models, drill jig fabrication, or in the insertion of the screws into the cadaveric spine. The evaluator was also blinded to the specific cadaver and specific vertebral level under evaluation.

\section{Results}

Appendix 2 shows our collected data, and Table 1 shows our results. Of the 50 pedicles, 47 screws were accurately inserted. The overall accuracy rate for CPS placement was $94 \%$ ( 47 of 50 ). The overall malposition rate was $4 \%$ for grade 1 ( 2 of 50 ) and 2\% for grade 2 ( 1 of 50). Safely inserted screws, combining the grade 0 and 1 categories, were as high as $98 \%$. Fig. 11 shows the accuracy rate for each cervical level.

Of the three total screw perforations, a glaring perforation was seen at $\mathrm{C} 3$ on one cadaver. The screw was medially misdirected because the template was not in total contact on the surface of the vertebra because of residual muscle soft tissue. This was an "unsafe screw placement"

Table 1. Accuracy rates per cervical level

\begin{tabular}{|c|c|c|c|c|}
\hline Cervical level & $\begin{array}{c}\text { Grade } 0 \\
\text { (no perforation) }\end{array}$ & $\begin{array}{c}\text { Grade } 1 \\
\text { (minor perforation) }\end{array}$ & $\begin{array}{c}\text { Grade } 2 \\
\text { (major perforation) }\end{array}$ & Accuracy rate $(\%)$ \\
\hline C3 & 9 & 0 & 1 & 90 \\
\hline C4 & 10 & 0 & 0 & 100 \\
\hline C5 & 9 & 1 & 0 & 90 \\
\hline C6 & 9 & 1 & 0 & 90 \\
\hline $\mathrm{C7}$ & 10 & 0 & 0 & 100 \\
\hline Total & 47 & 2 & 1 & 94 \\
\hline
\end{tabular}


(Fig. 12).

The remaining perforations were grade 1 perforations that occurred at $\mathrm{C} 5$ and $\mathrm{C} 6$ each on two different cadavers; both had lateral pedicle wall breach because the 4.0$\mathrm{mm}$ diameter screws that were inserted were too large for the diameter of the pedicles. The screws, however, were properly directed where intended. Because the medial wall was intact and the vertebral foramen had not been breached, this placement was considered to be a "safe placement."

Our screw placement had an accuracy of $94 \%$, and our safe screw placement had an accuracy of $98 \%$.

\section{Discussion}

Pedicle screw fixation of the cervical spine offers biomechanical advantages over lateral mass fixation techniques. Studies on CPS fixation show better stability than those of all other posterior fixation methods and conventional anterior techniques. The technique offers biomechanical advantages especially for patients with osteoporosis and those who require multilevel fixation because of its firm

\section{Cervical pedicle screw insertion accuracy}

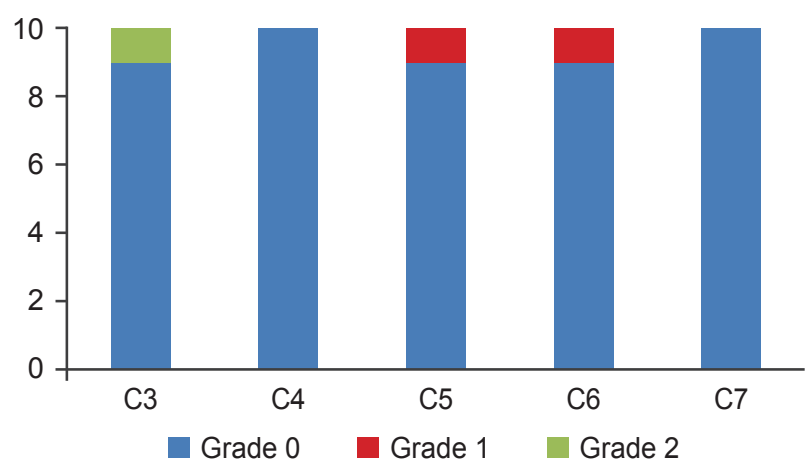

Fig. 11. Cervical screw accuracy. hold along the three columns of the spine. Increased stability is also very evident in torsional and extension loading. These biomechanical advantages have provided better deformity corrections, which have been shown to enhance the fusion rate, reduce the number of segments that need to be fused, ensure better capacity for screw repositioning, and allows early rehabilitation caused by the less restrictive postoperative immobilization in a wide variety of traumatic, congenital, infectious, neoplastic, and degenerative conditions of the cervical spine [1-4].

However, the method of CPS fixation is still technically demanding because it carries the risk of catastrophic damage to the surrounding neurovascular structures. The proximity of the pedicles to the spinal cord, nerve root, and vertebral arteries warrants a very precise screw placement during posterior instrumentation [10-12]. There is also wide anatomical variation in the size, shape, and even angulation of the cervical pedicles among individuals, which makes standardized techniques more inaccurate [79]. Pathological conditions may further distort the normal anatomy of the spine and make surgical navigation more difficult $[11,14]$.

Various methods have been explored for precise pedicle screw placement. These methods can be broadly grouped as follows: (1) techniques relying on morphometric measurements (anatomical landmarks and averaged angular dimensions) [2,6-10], (2) fluoroscopic-guided techniques $[5,6,12,13],(3)$ computerized IGSs $[4,6,12,15,16]$, and (4) techniques that use PSSTs [17-22]. Plain localization of the cervical pedicles using landmarks alone has an inaccuracy rate as high as $87.5 \%$, primarily because of topographic anatomical variability. Fluoroscopy-guided insertion for pedicle screw fixation has been the gold standard for safe and accurate placement. Accuracy rates have been reported to be as high as $85 \%-91 \%$. This technique has a fast-learning curve and a relatively economical setup.
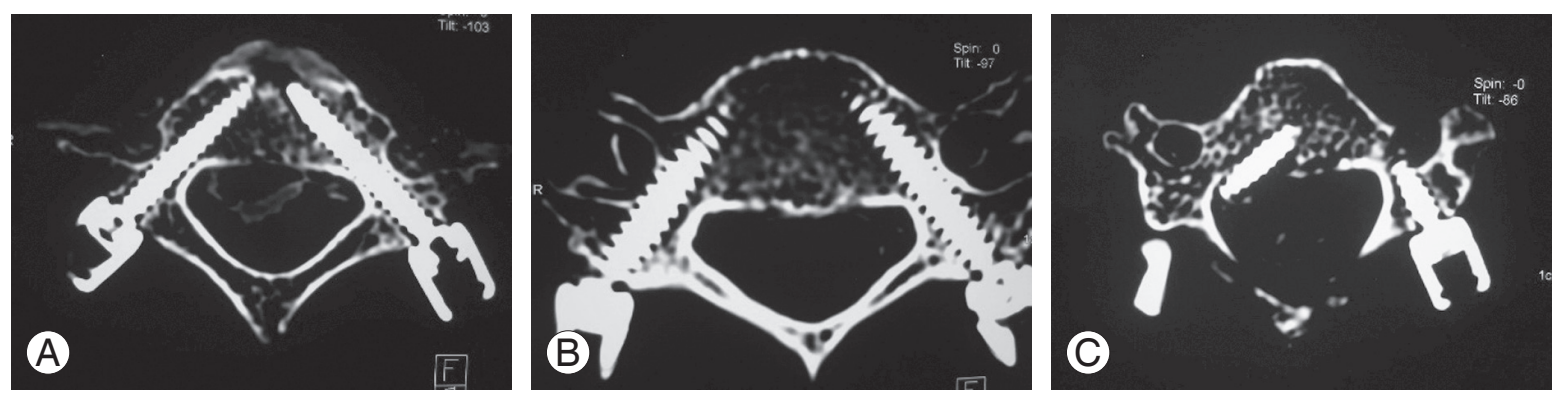

Fig. 12. Post-instrumentation computed tomography scans showing the accuracy of cervical pedicle screw insertions: grade 0 perforation of sample B, bilateral C3 (A); grade 1 perforation of sample $E$, right C6 (B); and grade 2 perforation of sample $A$, right C3 (C). 
However, it has the disadvantages of radiation exposure and limited maneuverability for the surgeon because of the space occupied by the image intensifier. The frequent utilization of a Mayfield apparatus hampers good fluoroscopic images as well. The proponents of IGS techniques claim high accuracy provided by the surgical navigation. IGS is performed by digitizing the patient's anatomy, combining the images into a computerized system, and integrating the surgical instruments into the digitized image background. This procedure allows the surgeon to navigate the surgical instruments and the bone in an improved virtual visual environment. However, the limitations of IGS include a significant learning curve, increased surgical time for the complicated calibration process, a specialized technical support, and the high cost of equipment. The small posterior structures of the cervical spine also provide a flimsy and limited anchorage for the essential optical arrays used in IGS.

The latest trends in PSSTs have facilitated accurate pedicle screw fixation particularly for the cervical spine because of recent advances in stereolithography or 3D printing [17-20,23]. The development of free-ware DICOM software readers allows creation of 3D-rendered images from CT and magnetic resonance imaging (MRI) and convert them to ".stl" files. By exporting these ".stl" files to commercially available office desktop 3D printers, we can now create a 3D biomodel of a patient's spine using rapid prototyping techniques. These 3D biomodels enable fabrication of PSSTs, which offer higher precision because they are tailored to the specific characteristics of the anatomy of an individual. These biomodels are "ready to use" with no need of any sophisticated setup. Design of the surgical guides can also be modified according to the surgeon's needs and have eliminated the need for expensive equipment and time-consuming intraoperative registration and calibration. Although this technology has been applied in many anatomical regions, such as the shoulder and knee, there is currently limited literature on its use in CPS insertion.

The use of CT-scan-based PSSTs has been previously reported by Berry [21]. He described a 3D template created using surgical planning software for insertion of pedicle screws. They reported high accuracy rates, reaching as high as $100 \%$ in some templates in an in vitro setting [21]. Fu et al. [22] showed accurate placement of anterior transpedicle screws using a template based on a 3D-printed model of a spine in an in vitro study. Sugawara et al. [24] achieved a mean deviation of $0.9 \mathrm{~mm}$ from their initial trajectory using their 3D-printed screw guides to determine the ideal entry points and angles of insertion for each vertebral body. Landi et al. [23] showed a maximum margin of error of $0.5 \mathrm{~mm}$ for their 3D-printed screw guides compared with the minimum margin of error obtained using neuronavigation. Lu et al. [25] manifested high accuracy rates for their templates using Mimic software for rapid processing of both 3D-printed spine models and specific screw guide templates.

Other similar studies have reported accurate screw placement for in vivo clinical settings. Miyamoto and Uno [26] earlier created a crude template made from CT cutouts as guides to the entry point and trajectories for CPSs. Kawaguchi et al. [27] used a life-sized 3D model to fabricate templates made of hard plastic as drill guides for inserting CPSs. Kaneyama et al. [28] used actual 3Dprinted screw guide templates to insert pedicle screws at $\mathrm{C} 2$ and the mid cervical spine with great accuracy. Their screw placement positions and screw guide templates were all digitally fashioned using multiplanar imaging software [27-29].

Our technique differs in that we visually inserted guide wires into the pedicles of a 3D-printed plastic biomodel of the cervical spine after carefully determining the proper entry point, orientation, and angle of insertion. This procedure allowed us to create manually fashioned screw guide templates using fast-setting acrylics molded over the inserted guide wires. Our acrylic molds can then serve as accurate guides into the pedicles of the cervical vertebrae. This technique also has the added benefits of providing a "haptic" feel and enables a meticulous evaluation of a true to scale $3 \mathrm{D}$ printed bio-model of the cervical spine even before actual the actual surgery and instrumentation. The technique allows determination of the pre-existing pathologies or anatomical variations that can otherwise influence the course of surgery. Our technique is a simple but a viable novel procedure for anyone who lacks the technical resources of operating CAD-CAM software and only requires a very basic desktop $3 \mathrm{D}$ printing machine.

Recently, entrepreneurial industries in developed countries now offer fabrication of these PSSTs as service providers [30]; surgeons simply send them their patient's CT or MRI images, and a company performs the $3 \mathrm{D}$ printing and prototyping of patient-specific surgical jigs. The latter is delivered ready for surgical utilization. This transaction, however, comes at an added cost with a lot of downtime. 
Table 2. Comparison of accuracy rates for different methods of cervical pedicle screw insertion

\begin{tabular}{|c|c|c|}
\hline Author/Year & Method analyzed for cervical pedicle screw insertion & Accuracy rate $(\%)$ \\
\hline Karaikovic et al. [9], 2001 & Landmarks & 83.2 \\
\hline Park et al. [10], 2014 & Landmarks & 94.1 \\
\hline Ludwig et al. [6], 2000 & Landmarks vs. IGS & 12.5 vs. 76 \\
\hline Takahashi et al. [31], 2012 & IGS & 92.1 \\
\hline Richter et al. [15], 2005 & Fluoroscopy-guided vs. IGS & 91.4 vs. 97 \\
\hline Hojo et al. [12], 2014 & Fluoroscopy-guided & 85.2 \\
\hline Miyamoto and Uno [26], 2009 & Patient specific surgical CT cutout template & 97 \\
\hline Lu et al. [25], 2009 & Patient specific surgical 3D template & 80.6 \\
\hline Kawaguchi et al. [27], 2012 & Patient specific surgical 3D template & 95.4 \\
\hline Fu et al. [22], 2013 & Patient specific surgical 3D template & 91.7 \\
\hline Kaneyama et al. [30], 2015 & Patient specific surgical 3D template & $94-100$ \\
\hline
\end{tabular}

IGS, image guided surgery; CT, computed tomography; 3D, three-dimensional.

We strongly believe that with a simple setup, anyone can start his own office desktop 3D biomodel prototyping to produce "do-it-yourself" patient-specific surgical jigs. This study demonstrated that a low-cost fabrication technique that uses 3D printing of an accurate patient-specific surgical drill guide for inserting pedicle screws in the cervical spine is practical and economical.

Comparing all techniques of safe pedicle screw insertion into the cervical spine, PSSTs appear to be a promising solution to the challenges and complications the procedure poses (Table 2). Our technique of producing drill guide templates constructed from 3D-printed plastic models based on DICOM images of actual human spines had a convincing accuracy of $94 \%$. We had three perforationsone major perforation (one breaching the central canal) and two minor perforations (both just slightly breaching the lateral pedicle walls). On closer analysis, our major perforation was caused by our failure to denude the bone of all soft tissues and not by misdirected drilling using defective drill-guide templates. This residual tissue prevented our PSST from resting snugly on the surface anatomy of the cervical vertebra. The two minor perforations were secondary to the size of our $4.0-\mathrm{mm}$ pedicle screws, which we had to use because we ran out of the standard $3.5-\mathrm{mm}$ screws for CPS fixation. The $4.0-\mathrm{mm}$ screws were just too large for the pedicles. These two perforations were still within the proper direction of the pedicles.

Perhaps no other surgical specialty is more dependent on preoperative templating than orthopedics. The recent advancements in stereolithographic technology have allowed us to literally add a new dimension in our preoperative templating. Presently, industry-fabricated patient-specific surgical guides cost anywhere from US $\$ 500-2,000$. Our 3D-Printed Surgical Template for the subaxial spine (C3-C7) costs 50.00 US\$. Our procedure is low cost but high technology based. It is simple, accurate, and very cost effective. The technology transfer is very easy and can be adopted by any orthopedic center. There is even a better advantage in producing your own $3 \mathrm{D}$ templates; the intangible benefit of a "haptic" feel of the cervical spine that will be operated upon. While fabricating our specific templates in this study, we realized the potential of being able to touch and feel the spinal models specific to patients before we operate on them. This "hands-on" experience can help to plan the exact demarcations for decompressions, precise fixation techniques, and even simulate stabilization constructs before the surgery is performed. This experience also eliminates the surprise factor of an unperceived anatomical variation because the 3D printed biomodels shows the precise anatomy of the spine to be operated on and provides an opportunity to make accurate measurements for implant sizing and precontouring. We believe that these benefits will translate to improved patient safety when performing delicate posterior cervical spine surgeries.

\section{Conclusions}

The use of a novel simplified patient-specific drill guide constructed using available office desktop stereolithogra- 
phy improved the accuracy of CPS placement in a cadaveric model.

\section{Conflict of Interest}

No potential conflict of interest relevant to this article was reported.

\section{References}

1. Bransford RJ, Lee MJ, Reis A. Posterior fixation of the upper cervical spine: contemporary techniques. J Am Acad Orthop Surg 2011;19:63-71.

2. Abumi K, Itoh H, Taneichi H, Kaneda K. Transpedicular screw fixation for traumatic lesions of the middle and lower cervical spine: description of the techniques and preliminary report. J Spinal Disord 1994;7:19-28.

3. Lee JH, Park JW, Shin YH. The insertional torque of a pedicle screw has a positive correlation with bone mineral density in posterior lumbar pedicle screw fixation. J Bone Joint Surg Br 2012;94:93-7.

4. Ludwig SC, Kramer DL, Vaccaro AR, Albert TJ. Transpedicle screw fixation of the cervical spine. Clin Orthop Relat Res 1999;(359):77-88.

5. Mohi Eldin MM. Cervical pedicle screw fixation: anatomic feasibility of pedicle morphology and radiologic evaluation of the anatomical measurements. Asian Spine J 2014;8:273-80.

6. Ludwig SC, Kramer DL, Balderston RA, Vaccaro AR, Foley KF, Albert TJ. Placement of pedicle screws in the human cadaveric cervical spine: comparative accuracy of three techniques. Spine (Phila Pa 1976) 2000;25:1655-67.

7. Karaikovic EE, Kunakornsawat S, Daubs MD, Madsen TW, Gaines RW Jr. Surgical anatomy of the cervical pedicles: landmarks for posterior cervical pedicle entrance localization. J Spinal Disord 2000;13:63-72.

8. Lee DH, Lee SW, Kang SJ, et al. Optimal entry points and trajectories for cervical pedicle screw placement into subaxial cervical vertebrae. Eur Spine J 2011;20: 905-11.

9. Karaikovic EE, Yingsakmongkol W, Gaines RW Jr. Accuracy of cervical pedicle screw placement using the funnel technique. Spine (Phila Pa 1976) 2001;26: 2456-62.

10. Park JH, Jeon SR, Roh SW, Kim JH, Rhim SC. The safety and accuracy of freehand pedicle screw placement in the subaxial cervical spine: a series of 45 consecutive patients. Spine (Phila Pa 1976) 2014;39:2805.

11. Uehara M, Takahashi J, Hirabayashi H, et al. Perforation rates of cervical pedicle screw insertion by disease and vertebral level. Open Orthop J 2010;4:142-6.

12. Hojo Y, Ito M, Suda K, Oda I, Yoshimoto H, Abumi K. A multicenter study on accuracy and complications of freehand placement of cervical pedicle screws under lateral fluoroscopy in different pathological conditions: CT-based evaluation of more than 1,000 screws. Eur Spine J 2014;23:2166-74.

13. Ishikawa $Y$, Kanemura $T$, Yoshida G, et al. Intraoperative, full-rotation, three-dimensional image (O-arm)based navigation system for cervical pedicle screw insertion. J Neurosurg Spine 2011;15:472-8.

14. Singer G. Occupational radiation exposure to the surgeon. J Am Acad Orthop Surg 2005;13:69-76.

15. Richter M, Cakir B, Schmidt R. Cervical pedicle screws: conventional versus computer-assisted placement of cannulated screws. Spine (Phila Pa 1976) 2005;30:2280-7.

16. Van de Kelft E, Costa F, Van der Planken D, Schils F. A prospective multicenter registry on the accuracy of pedicle screw placement in the thoracic, lumbar, and sacral levels with the use of the $\mathrm{O}$-arm imaging system and StealthStation Navigation. Spine (Phila Pa 1976) 2012;37:E1580-7.

17. Izatt MT, Thorpe PL, Thompson RG, et al. The use of physical biomodelling in complex spinal surgery. Eur Spine J 2007;16:1507-18.

18. Sherekar RM, Pawar AN. Application of biomodels for surgical planning by using rapid prototyping: a review and case studies. Int J Innov Res Adv Eng 2014;1:263-71.

19. Paiva WS, Amorim R, Bezerra DA, Masini M. Aplication of the stereolithography technique in complex spine surgery. Arq Neuropsiquiatr 2007;65:443-5.

20. Popescu D, Anania DF, Amza CG, Cicic DT. Design and rapid manufacturing of patient-specific spinal surgical guides: a survey. Proc Manuf Syst 2012;7: 115-20.

21. Berry E, Cuppone M, Porada S, et al. Personalised image-based templates for intra-operative guidance. Proc Inst Mech Eng H 2005;219:111-8.

22. Fu M, Lin L, Kong X, et al. Construction and accura- 
cy assessment of patient-specific biocompatible drill template for cervical anterior transpedicular screw (ATPS) insertion: an in vitro study. PLoS One 2013;8: e53580.

23. Landi A, Gregory F, Mancarella C, Delfini R. 3D printed tubular guides for pedicle screw placement: the answer for the need of a greater accuracy in spinal stabilization. Orthop Muscular Syst 2015;4:e116.

24. Sugawara T, Higashiyama N, Kaneyama S, et al. Multistep pedicle screw insertion procedure with patientspecific lamina fit-and-lock templates for the thoracic spine: clinical article. J Neurosurg Spine 2013;19:18590.

25. Lu S, Xu YQ, Lu WW, et al. A novel patient-specific navigational template for cervical pedicle screw placement. Spine (Phila Pa 1976) 2009;34:E959-66.

26. Miyamoto $\mathrm{H}$, Uno K. Cervical pedicle screw insertion using a computed tomography cutout technique. J Neurosurg Spine 2009;11:681-7.

27. Kawaguchi Y, Nakano M, Yasuda T, Seki S, Hori T, Kimura T. Development of a new technique for pedicle screw and Magerl screw insertion using a 3-dimensional image guide. Spine (Phila Pa 1976) 2012;37:1983-8.

28. Kaneyama S, Sugawara T, Sumi M, Higashiyama N, Takabatake M, Mizoi K. A novel screw guiding method with a screw guide template system for posterior C-2 fixation: clinical article. J Neurosurg Spine 2014; 21:231-8.

29. Kaneyama S, Sugawara T, Higashiyama N, Takabatake M, Sumi M, Mizoi K. The availability of the screw guide template system for the insertion of mid-cervical pedicle screw: technical note. J Spine 2014;3:151.

30. Kaneyama S, Sugawara T, Sumi M. Safe and accurate midcervical pedicle screw insertion procedure with the patient-specific screw guide template system. Spine (Phila Pa 1976) 2015;40:E341-8.

31. Takahashi J, Hirabayashi H, Hashidate H, et al. Perforation rates of cervical pedicle screw inserted from C3 to C6: a retrospective analysis of 78 patients over a period 5 of 14 years. In: Chung KJ, editor. Spine surgery. Rijeka: InTech; 2012. p.113-20. 
Appendix 1. Profiles of cadaveric specimens obtained from Department of Anatomy, College of Medicine, University of the Philippines, Manila

\begin{tabular}{|c|c|c|c|c|}
\hline Cadaver & Issued reference number & Age & Sex & Cause of death/Diagnosis \\
\hline Specimen A & 2012-001 (T5) & Unknown & Female & $\begin{array}{l}\text { Septic shock } \\
\text { Psychosis }\end{array}$ \\
\hline Specimen B & 2012-039 (T12) & Unknown & Female & $\begin{array}{l}\text { Acute myocardial infarction } \\
\text { Chronic hypertension } \\
\text { Schizophrenia }\end{array}$ \\
\hline Specimen C & 2011-062 (T11) & Unknown & Male & $\begin{array}{l}\text { Pneumonia } \\
\text { Pulmonary tuberculosis }\end{array}$ \\
\hline Specimen D & 2012-035 (T8) & Unknown & Male & $\begin{array}{l}\text { Septic shock } \\
\text { Schizophrenia }\end{array}$ \\
\hline Specimen E & $2012-026(\mathrm{~T} 2)$ & $53 \mathrm{yr}$ & Male & $\begin{array}{l}\text { Sepsis } \\
\text { Pulmonary tuberculosis } \\
\text { Pneumonia } \\
\text { Psychosis }\end{array}$ \\
\hline
\end{tabular}

Appendix 2. CT scan evaluation of cervical pedicle screw insertion using axial cuts

\begin{tabular}{|c|c|c|c|}
\hline $\mathrm{CT}$ frame review number & Cervical vertebra & Left & Right \\
\hline 1 & A C3 & 0 & 1 \\
\hline 2 & A C4 & 0 & 0 \\
\hline 3 & A C5 & 0 & 0 \\
\hline 4 & A C6 & 0 & 0 \\
\hline 5 & A C7 & 1 & 0 \\
\hline 6 & B C3 & 0 & 0 \\
\hline 7 & B C4 & 0 & 0 \\
\hline 8 & B C5 & 0 & 0 \\
\hline 9 & B C6 & 0 & 0 \\
\hline 10 & B C7 & 0 & 0 \\
\hline 11 & D C3 & 0 & 0 \\
\hline 12 & $\mathrm{D} C 4$ & 0 & 0 \\
\hline 13 & D C5 & 0 & 0 \\
\hline 14 & D C6 & 0 & 0 \\
\hline 15 & D C7 & 0 & 0 \\
\hline 16 & E C3 & 0 & 1 \\
\hline 17 & E C4 & 0 & 0 \\
\hline 18 & E C5 & 0 & 0 \\
\hline 19 & E C6 & 0 & 1 \\
\hline 20 & E C7 & 0 & 0 \\
\hline 21 & F C3 & 0 & 0 \\
\hline 22 & F C4 & 0 & 0 \\
\hline 23 & F C5 & 0 & 0 \\
\hline 24 & F C6 & 0 & 0 \\
\hline 25 & F C7 & 0 & 0 \\
\hline
\end{tabular}

CT, computed tomography; Grade 0, no perforation; Grade 1, minor perforation; Grade 2, major perforation. 